JURNAL REKA YASA PROSES
Volume 10 No.2, 2016, hal. 43-47
Journal homepage: http://journal.ugm.ac.id/jrekpros

\title{
Pengaruh Variasi Organic Loading Rate Sampah Buah Jeruk terhadap Produksi Biohidrogen pada Reaktor Kontinu
}

\author{
Baruna Sakti Wicaksono Bonanza* dan Sarto \\ Departemen Teknik Kimia, Fakultas Teknik, Universitas Gadjah Mada \\ J1. Grafika No. 2 Kampus UGM, Yogyakarta, 55281 \\ *Alamat Korespondensi: baruna.bonanza@gmail.com
}

\begin{abstract}
A B S T R A CT
Biohydrogen is a potential alternative energy generated through the process of dark fermentation of organic waste. This research aims to determine the effect of organic loading rate $(O L R)$ variations of orange waste on biohydrogen production. This research dealt with the production of biohydrogen in the continuous system. The reactor was equipped with circulation and operated anaerobically. The inoculum was taken from the sludge of the biogas installation in Gemah Ripah Fruit Market. Orange waste was used in three variations of organic loading rate $(O L R)$ at 2.2, 2.5, and $3.1 \mathrm{~L} /$ day. The results revealed that the daily productions of gas for those OLR are about 15, 35, and $26 \mathrm{~L} / \mathrm{day}$ respectively. Futhermore, for OLR of $2.5 \mathrm{~L} /$ day the total solid decreased from about 8 to $5 \%$.
\end{abstract}

Keywords: Biohydrogen, dark fermentation, orange waste, organic loading rate

\begin{abstract}
A B S T R A K
Biohidrogen merupakan salah satu jenis energi alternatif yang dapat dihasilkan dari proses fermentasi gelap (dark fermentation) sampah organik. Penelitian ini bertujuan untuk mengetahui pengaruh variasi organic loading rate (OLR) sampah buah jeruk terhadap produksi biohidrogen. Pada penelitian ini produksi biohidrogen dilakukan menggunakan sistem kontinu. Reaktor yang digunakan dilengkapi dengan sirkulasi dan dijaga pada kondisi anaerob. Inokulum berasal dari sludge dari instalasi biogas Pasar Buah Gemah Ripah. Substrat yang digunakan adalah buah jeruk, sedangkan variabel yang dipelajari adalah OLR yang divariasikan sebesar 2,2; 2,5; dan 3,1 L/hari. Hasil penelitian menunjukkan bahwa produksi gas untuk OLR tersebut berturut-turut sekitar 15, 35, dan 26 L/hari. Pada OLR 2,5 L/hari, terjadi penurunan total solid dari sekitar $8 \%$ menjadi sekitar 5\%.
\end{abstract}

Kata kunci: Biohidrogen, dark fermentation, jeruk, organic loading rate

\section{Pendahuluan}

Seiring dengan perkembangan ilmu pengetahuan dan teknologi, kebutuhan energi di dunia semakin meningkat. Kebutuhan energi di Indonesia menempati 12 dari 20 negara pengguna energi terbesar di dunia yaitu sebesar 8,7 EJ (exajoules) atau setara dengan 2416,6 TWh (Terawatt hour) (Hijauku.com, 2013). Untuk memenuhi pasokan kebutuhan energi, salah satu tantangannya adalah mencari alternatif energi terbarukan yang ramah lingkungan seperti bioetanol, bio-diesel biohidrogen $\left(\mathrm{Bio}-\mathrm{H}_{2}\right)$, dan bio-butandiol (Bio-BD) (Chang dkk., 2002). 
Hidrogen merupakan salah satu sumber energi alternatif yang ramah lingkungan. Energi hasil kalor pembakaran hidrogen mencapai 120,1 $\mathrm{MJ} / \mathrm{Kg}$, hampir tiga kali lipat lebih besar daripada energi yang dihasilkan pembakaran gasolin (Kim dkk., 2006). Salah satu sumber bahan baku pembuatan hidrogen adalah limbah biomassa. Hidrogen diproduksi melalui proses fermentasi gelap. Hidrogen yang diperoleh dari bahan biomassa disebut biohidrogen. Salah satu kelebihan proses produksi biohidrogen dengan fermentasi gelap adalah tidak membutuhkan energi yang besar.

Berdasarkan Badan Pusat Statistik Indonesia (2011), produksi buah jeruk dalam negeri mencapai 454,83 ribu ton dan konsumsi masyarakat mencapai 178,68 ribu ton. Limbah buah jeruk memiliki kandungan glukosa yang cukup besar (Pourbafrani, 2010). Widmer dkk. (2010) menyatakan limbah buah jeruk mengandung gula (30-40\%), pektin (15-25\%), selulosa (8-10\%), hemiselulosa (5-7\%) dan minyak atsiri (0,4-2,6\%). Penelitian tentang produksi biohidrogen dengan fermentasi secara batch telah banyak dilakukan tetapi pelaksanaan secara kontinu masih sangat jarang. Cahyari dkk. (2013) melakukan penelitian produksi biohidrogen secara kontinu dalam fermentor tanpa sirkulasi. Salah satu faktor utama yang mempengaruhi fermentasi secara kontinu adalah organic loading rate (OLR). Pemilihan OLR yang terlalu tinggi menyebabkan akumulasi inhibitor dari sampah buah jeruk sehingga menghambat proses produksi, sedangkan OLR yang terlalu rendah menyebabkan kekurangan pasokan nutrisi untuk dikonsumsi mikroorganisme sehingga menghasilkan produk yang rendah (Pandiyan dan Gudipudi, 2013). Tulisan ini merupakan hasil kajian awal pengaruh OLR pada produksi biohidrogen dalam fermentor dengan sirkulasi.

\section{Metode Penelitian}

\subsection{Bahan Penelitian}

Bahan utama yang digunakan dalam penelitian ini adalah sampah buah jeruk yang diperoleh dari Pasar Buah Gemah Ripah,
Gamping Yogyakarta. Sebagai sumber mikroorganisme, digunakan inokulum berupa sludge dari limbah buah yang diperoleh dari instalasi biogas Pasar Buah Gemah Ripah Gamping, Yogyakarta. Pengaturan nutrisi pada reaktor menggunakan pepton, $\mathrm{NaOH}$ pellet, $L$ cystein Hydrocloride, $\mathrm{HCl} 37 \%$, Yeast Extract, $\mathrm{Na}_{2} \mathrm{HPO}_{4}, \mathrm{KH}_{2} \mathrm{PO}_{4}, \mathrm{MgSO}_{4} .7 \mathrm{H}_{2} \mathrm{O}$, dan Resazurin yang semuanya diperoleh dari Laboratorium Teknik Pangan dan Bioproses, Departemen Teknik Kimia UGM. Untuk membuat kondisi anaerob, digunakan gas nitrogen teknis.

\subsection{Rangkaian Alat Penelitian}

Rangkaian alat yang digunakan dalam penelitian ini disajikan pada Gambar 1.

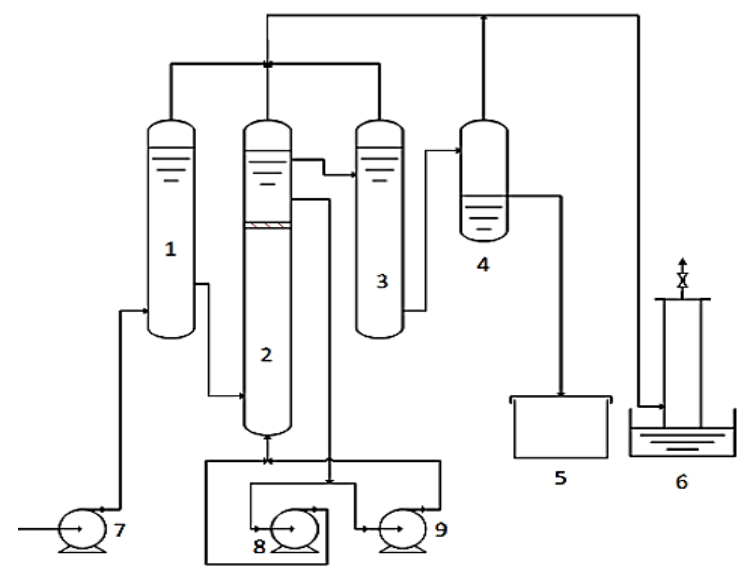

Keterangan :

1. Tangki Input

2. Reaktor

6. Gas Meter

3. Tangki Antara

7. Pompa Input

4. Tangki Effluent

8. Pompa Sirkulasi 1

9. Pompa Sirkulasi 2

5. Penampung Effluent

Gambar 1. Rangkaian alat penelitian

\subsection{Cara Penelitian}

\subsubsection{Persiapan dan Tes Kebocoran Alat}

Rangkaian alat penelitian dipastikan tidak bocor dengan cara menutup seluruh lubang pengeluaran reaktor (digester) kemudian diisi air dan didiamkan selama 24 jam. Tes kebocoran gas juga dilakukan pada digester, karena produk berupa gas. Pertama, lubang keluaran 1, 2, 3, dan effluent ditutup, kemudian dialirkan udara dari saluran input. Pada saat yang bersamaan bagian sambungan digester diolesi dengan sabun, jika terbentuk gelembung, maka digester masih 
bocor, sehingga pada bagian yang bocor harus dilem ulang.

\subsubsection{Pretreatment Inokulum}

Inokulum yang digunakan dalam penelitian ini adalah mikroorganisme campuran asal digester biogas limbah buah, limbah tahu dan kotoran sapi. Bakteri metanogen dihambat pertumbuhannya dengan perlakuan pengasaman (acid treatment) dengan ditambahkan $\mathrm{HCl} 2 \mathrm{M}$ hingga mencapai $\mathrm{pH} 3$ kemudian didiamkan selama 24 jam, kemudian $\mathrm{pH}$ dinaikkan kembali menjadi 7 dengan ditambahkan $\mathrm{NaOH} 2 \mathrm{M}$ (Ren dkk., 2008). Untuk memperbanyak jumlah bakteri, inokulum tersebut dikayakan dengan medium Pepton-Yeast-Glukosa (PYG) tiga kali.

\subsubsection{Persiapan Substrat Buah Jeruk}

Sampah buah jeruk yang diperoleh dari Pasar Buah Gemah Ripah dikupas dan dipisahkan bagian buahnya. Bagian buah jeruk dibuat juice, diambil sebagai slurry, dan dianalisis kandungan total solid (TS) dan volatil solid (VS). Jumlah buah jeruk yang disiapkan sesuai dengan kebutuhan loading rate yaitu 2,$2 ; 2,5$; dan 3 L/hari.

\subsubsection{Pelaksanaan Proses Produksi Biohidrogen}

Sebelum inokulum dan bahan umpan buah jeruk dimasukkan ke dalam biodigester, fermentor dialiri gas nitrogen untuk mengusir oksigen di dalamnya. Hal ini dilakukan agar proses berlangsung secara anaerob. Selanjutnya, inokulum yang sudah di-pretreatment dimasukkan ke dalam biodigester dan dilanjutkan dengan penamabahan slurry jeruk sesuai dengan loading rate nya. Pengumpanan dilakukan setiap hari dengan sirkulasi secara terus-menerus untuk memastikan homogenitas substrat. Volume gas hasil diukur, dan diambil untuk dianalisis kadar hidrogennya. Adapun sampel substrat diambil baik umpan maupun effluentnya untuk dianalisis kadar total solidnya.

Perubahan OLR dilakukan dari kecil ke besar, yaitu OLR 2,2 L/hari selama 5 hari, kemudian dinaikkan menjadi 2,5 L/hari selama 5 hari, dan diakhiri OLR 3,1 L/hari selama 4 hari.

\section{Hasil dan Pembahasan}

Volume gas hasil total harian pada setiap OLR disajikan dalam Gambar 2.

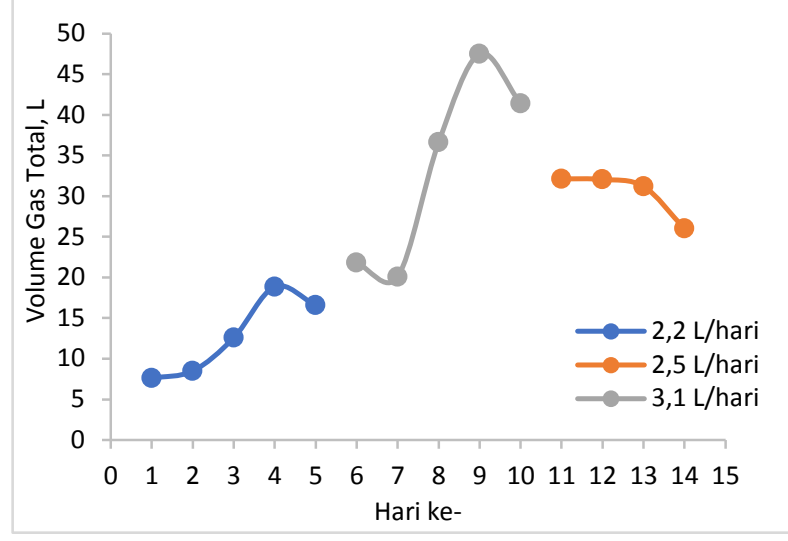

Gambar 2. Produksi volum biogas pada variasi nilai OLR

Gambar 2 menunjukkan bahwa ada perbedaan volume gas yang dihasilkan oleh ketiga OLR meskipun tidak stabil. Ketidakstabilan produksi gas pada OLR tertentu disebabkan oleh dinamika proses fermentasi akibat perubahan umpan baik akibat perubahan OLR maupun perubahan kondisi jeruk. Jumlah gas hasil tertinggi terjadi pada OLR 2,5 L/hari yaitu sekitar $35 \mathrm{~L} /$ hari, kemudian diikuti oleh OLR 3,1 L/hari (sekitar 26 L/hari), dan terkecil adalah pada OLR 2,2 L/hari (sekitar $15 \mathrm{~L} /$ hari). Hal ini sesuai dengan hasil penelitian Cahyari dkk. (2013) bahwa OLR terbaik terjadi pada 2,6 $\mathrm{gVS} / \mathrm{L} /$ hari untuk rentang variasi OLR 1,8-3,6 gVS/L/hari. Kecilnya volume gas hasil pada OLR 2,2 L/hari disebabkan oleh rendahnya kadar substrat di dalam fermentor. Adapun fenomena lebih rendahnya volume gas hasil pada OLR 3,1 L/hari dibandingkan dengan volume gas hasil pada OLR 2,5 L/hari diduga akibat terlalu banyaknya substrat sehingga menghambat proses fermentasi.

Hasil analisis kadar hidrogen dalam gas hasil ditunjukkan pada Gambar 3. Dari Gambar 3 dapat dilihat bahwa kadar gas hidrogen untuk ketiga OLR tidak berbeda secara bermakna, yaitu sekitar 2,5\%, meskipun pola perubahannya berbeda. Hasil serupa didapatkan oleh Kim dkk. (2011). Adapun alasannya adalah bahwa kadar hidrogen dalam gas hasil dipengaruhi oleh $\mathrm{pH}$ dan jalur metabolismenya. Rendahnya kadar hidrogen dalam gas hasil disebabkan oleh tidak sempurnanya proses anaerobik akibat adanya 
oksigen yang terbawa bersama substrat pada proses pengumpanan baik akibat pemompaan maupun penampungan di tangki input.

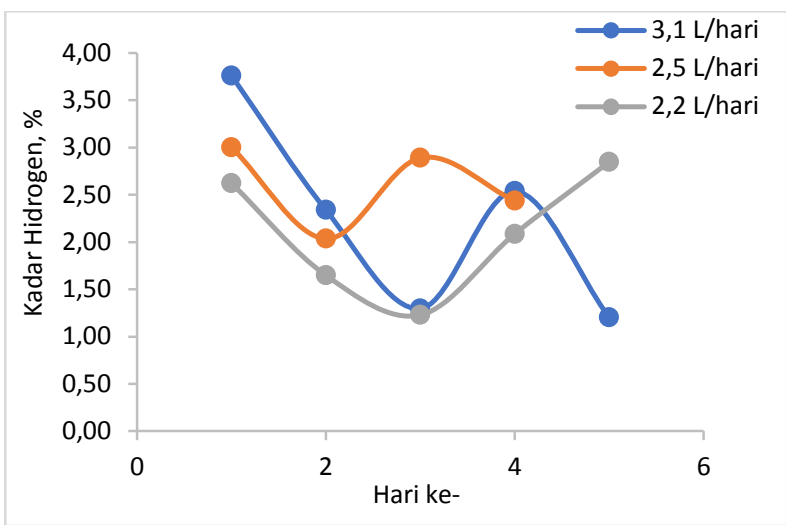

Gambar 3. Grafik hubungan kadar gas hidrogen dengan waktu.

Total solid (TS) merupakan salah satu indikator yang menjadi acuan analisis efektivitas fermentasi. Total solid menunjukkan kandungan padatan (jumlah volatile solid dan kadar abu) dalam suatu substrat dan dihitung dengan Persamaan (1).

$\% T S=\frac{(A-B)}{(D-B)} \times 100 \%$

dengan $\%$ TS = Total Solid, $\%$

$\mathrm{A}=$ Berat krus + sampel kering, gram

$\mathrm{B}=$ Berat krus kosong, gram

$\mathrm{D}=$ Berat krus + sampel basah, gram

Analisis TS hanya dilakukan pada OLR terbaik, yaitu 2,5 L/hari. Data hubungan \% TS dengan waktu pada OLR 2,5 L/hari yang didapat pada penelitian ini disajikan dalam Gambar 4.

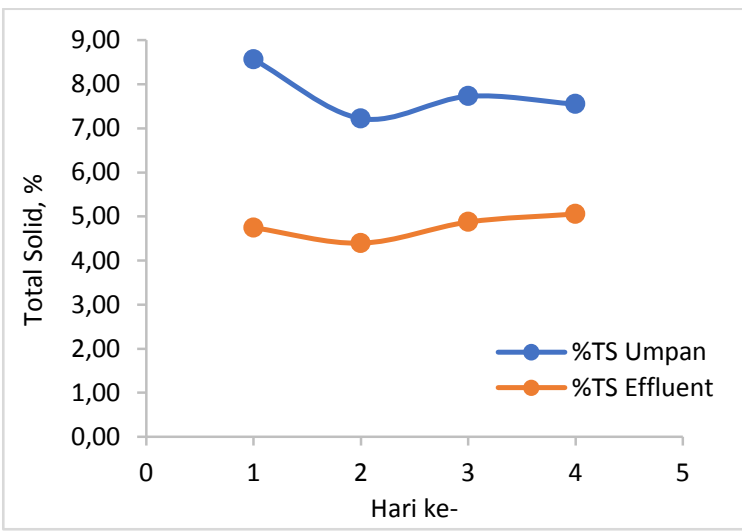

Gambar 4. Grafik hubungan antara \%TS dengan waktu.
Gambar 4 menunjukkan bahwa nilai TS pada umpan selalu lebih tinggi daripada nilai TS pada effluent. Nilai TS pada umpan berkisar antara 7,2 sampai dengan $8,3 \%$, sedangkan nilai TS effluent berkisar antara 4,4 sampai dengan $5,1 \%$. Hal ini menggambarkan adanya konversi TS menjadi gas.

\section{Kesimpulan}

Pada kisaran OLR antara 2,2-3,1 L/hari, volume gas tertinggi pada OLR 2,5L/hari, yaitu sebesar $35 \mathrm{~L} / \mathrm{hari}$. Adapun volume gas hasil pada OLR 2,2 dan 3,1 L/hari berturut-turut sekitar 15 dan $26 \mathrm{~L} /$ hari. Pada OLR 2,5 L/hari, terjadi penurunan total solid dari sekitar $8 \%$ menjadi sekitar $5 \%$.

\section{Daftar Pustaka}

Cahyari, K, Hidayat M, Sarto, Syamsiyah S, (2013), "Effect of Initial Substrate Concentration on Biohydrogen Production CFrom Orange and Melon Fruit Waste through Dark Fermentation", $6^{\text {th }}$ Regional Conference on Chemical Engineering. Manila Philiphines.

Chang, J.S., Lee, K.S., and Lin, P.J., 2002, "Biohydrogen production with fixed-bed bioreactors", Int. J. Hydrogen Energy, pp. 27, 1167-1174.

http://www.hijauku.com/2013/05/30/inilah-20negara-pengguna-energi-terbesar-di-dunia/ diakses pada tanggal 5 Maret 2016.

Kim, D.H., Han, S.K., Kim, S.H., dan Shin, H.S., 2006, "Effect of Gas Sparging on Continous Fermentive Hidrogen Production", International Journal of Hidrogen Energy, Vol. 31, 2158-2169.

Kim, D.H., Kim, S.H., Jung, K.W., Kim, M.S., Shin, H.S., (2011), "Effect of initial pH independent of operational $\mathrm{pH}$ on hydrogen fermentation of food waste", Biosource. Technol,, 102, 8646-8652.

Pandiyan, I., dan Gudipudi, S., 2013, "Effect of Fruit Flavor Compounds on Biogas Production", Tesis, Universitas of Boras, Swedia. 
Pourbafrani M, Forgács G, Horváth IS, Niklasson C, Taherzadeh MJ. Production of biofuels, limonene and pectin from citrus wastes. Bioresour Technol 2010;101:4246-50.

Ren, N., Guo, W., Wang, X., Xiang, W., Liu, B., Wang, X., Ding, J., Chen, Z., 2008, Effects of different pretreatment methods on fermentation types and dominant bacteria for hydrogen production, Int J Hydrogen Energy, $33,4318-4324$.
Widmer, W., Zhou, W., Grrohman, K., 2010, Pretreatmen effect on orange processing waste for making ethanol by simultaneous saccharification and fermentation. Bioresource Tech, 101, 5242-5249. 